\title{
Mediastinal lymph node metastases in thyroid cancer: surgery without limits
}

\author{
Elena Marrama ${ }^{1}$, Vittorio Aprile ${ }^{1}$, Agnese Nesti ${ }^{1}$, Diana Bacchin ${ }^{1}$, Gabriele Materazzi ${ }^{2}$, Marco Lucchi ${ }^{1}$ \\ ${ }^{1}$ Division of Thoracic Surgery, ${ }^{2}$ Division of Endocrine Surgery, Department of Surgical, Medical, Molecular, Pathology and Critical Care, University \\ Hospital of Pisa, Pisa, Italy \\ Correspondence to: Elena Marrama. Via Paradisa 2, Ospedale Cisanello, Pisa, Italy. Email: elenamarrama@gmail.com.
}

\begin{abstract}
Metastases to lymph nodes of the superior mediastinum have been found in up to $10 \%$ of patients with thyroid carcinoma. The treatment of mediastinal lymph node metastases in thyroid cancer is still far from being standardized. However, in selected cases, especially in case of radioiodine ablation and radiation therapy failure, a surgical resection may improve the patients' survival in addition to the symptomatic benefits. We report our experience in four consecutive patients who underwent extended mediastinal surgery for large lymph node metastases from thyroid cancer during the last year. All patients were pre-operatory evaluated by a multidisciplinary team involving endocrinologist, anaesthesiologist and surgeons. Surgery was carried out in all cases in two steps, firstly through a cervicotomy in order to remove the eventual local recurrence and ensure a radical neck dissection bilaterally and then by sternotomy, in order to dissect all the lymphadenopathies from the mediastinal structures. Two patients (50\%) had an extended vascular infiltration and the extracorporeal circulation (ECC) and, at least, one vascular graft, were needed. No intraoperative or perioperative mortality occurred in this series. Two patients (50\%) presented a sternal dehiscence that required a second surgery and a prolonged postoperative hospital stay. In all cases the surgery was radical, and the histological report revealed a macroscopic complete resection and, up to date, no recurrences were found. When feasible, surgery is more effective than systemic therapy in the treatment of thyroid cancer recurrences, especially for medullary thyroid cancer in which radioiodine therapy is ineffective and should always be evaluated in case of vascular infiltration or symptomatic patients. Moreover, due to diversity and complexity of the cervical and mediastinal structures that may be involved, a multidisciplinary medical team should always be guaranteed during the surgery.
\end{abstract}

Keywords: Lymph nodes metastases; multidisciplinary surgery; cases report

Received: 05 November 2019; Accepted: 21 November 2019; Published: 31 December 2019.

doi: $10.21037 /$ ccts.2019.11.09

View this article at: http://dx.doi.org/10.21037/ccts.2019.11.09

\section{Introduction}

Thyroid cancer is the most common endocrine malignancy and accounts for approximately 25,000 and 30,000 new cases each year in Europe and the US, respectively (1-3).

Up to $30 \%$ of patients with a thyroid cancer develops distant metastases during their lifetime and most of them by involving lymph nodes. Metastases of the superior mediastinal lymph nodes have been found in up to $10 \%$ of patients with thyroid carcinoma $(4,5)$.

The metastatic lymphadenopathy usually arises from the cervical region and descends along the mediastinum, behind the great mediastinal vessels. According to Sweet, most of the retrosternal lymphadenopathies are found in the antero-superior compartment of the mediastinum while, rarely are located retrotracheally or even in the posterior mediastinum (6).

The treatment of mediastinal lymph node metastases in thyroid cancer is still far from being standardized.

In advanced metastatic thyroid carcinoma, surgery has often only a palliative role in improving the symptoms (such as dysphagia, dyspnoea and obstructive sleep apnoea) 
Table 1 Patients who underwent mediastinal surgery for extended lymph node metastases from thyroid cancer during the last year

\begin{tabular}{|c|c|c|c|c|}
\hline Characteristics & Patient 1 & Patient 2 & Patient 3 & Patient 4 \\
\hline Endocrine anamnesis & Medullary thyroid carcinoma & Medullary thyroid carcinoma & Papillary thyroid carcinoma & $\begin{array}{l}\text { Solid undifferentiated } \\
\text { thyroid carcinoma }\end{array}$ \\
\hline $\begin{array}{l}\text { Pre-operative chemo/ } \\
\text { radiation therapy }\end{array}$ & No & Somatostatin analogue & No & No \\
\hline Surgical approach & Cervicotomy/sternotomy & Cervicotomy/sternotomy & $\begin{array}{l}\text { Cervicotomy/sternotomy + } \\
\text { extracorporeal circulation }\end{array}$ & $\begin{array}{l}\text { Cervicotomy/sternotomy }+ \\
\text { extracorporeal circulation }\end{array}$ \\
\hline Type of surgery & Lymphadenectomy & $\begin{array}{l}\text { Thyroidectomy + } \\
\text { Lymphadenectomy }\end{array}$ & $\begin{array}{c}\text { Thyroidectomy/ } \\
\text { lymphadenectomy/left } \\
\text { anonymous vein removal } \\
\text { +vascular graft }\end{array}$ & $\begin{array}{c}\text { Thyroidectomy/ } \\
\text { parathyroidectomy/ } \\
\text { lymphadenectomy and } \\
\text { vascular graft }\end{array}$ \\
\hline Follow up & Alive & Alive & Alive & Alive \\
\hline Post-surgical therapy & no & no & $\mathrm{I}-131$ & $\mathrm{I}-131$ \\
\hline Time of surgery (min) & 205 & 260 & 450 & 450 \\
\hline Complications & no & Moderate bleeding & $\begin{array}{l}\text { Sternotomy dehiscence } \\
\text { (surgery) }\end{array}$ & $\begin{array}{c}\text { Sternotomy dehiscence } \\
\text { (surgery) }\end{array}$ \\
\hline $\begin{array}{l}\text { Post operative stay } \\
\text { (days) }\end{array}$ & 7 & 6 & 100 & 55 \\
\hline
\end{tabular}

or the syndromes (such as mediastinal mass syndrome or endocrine/paraneoplastic syndromes). However, in selected cases, especially after the systemic and radiation therapy failure, surgery may improve the patients' survival in addition to the symptomatic benefits (7-10).

We present the following cases in accordance with the CARE Guidelines.

\section{Cases presentation}

In this case series, we report our experience in four consecutive patients who underwent mediastinal surgery for extended lymph node metastases from thyroid cancer during the last year from January 2019 to July 2019), as reported in Table 1. All patients were pre-operatory evaluated by a multidisciplinary team involving an endocrinologist, an anaesthesiologist and several surgeons of different specialities. Surgery was conducted both through a cervicotomy in order to remove the eventual local recurrence and ensure an adequate neck dissection bilaterally, and then by sternotomy to isolate all the mediastinal structures from the lymphadenopathy. The second step was performed by a multidisciplinary surgical equipe including a thoracic, a vascular, an endocrine and a cardiac surgeon. Two patients $(50 \%)$ had an extended vascular infiltration and the use of extracorporeal circulation (ECC) was needed in order to guarantee an effective vascular replacement.

\section{Patient 1}

A 66-years-old man was referred to our Department due to recurrence of medullary carcinoma in the site of the previous thyroidectomy associated to cervical and mediastinal lymph nodes metastases.

In 2016 the patient underwent total thyroidectomy for medullary micro-carcinoma with metastases to neck central compartment lymph nodes (pT1aN1Mx) associated with thyroid papillary carcinoma with multifocal follicular variant (pT1aN0M0).

During the surveillance, a chest computed tomography (CT) (Figure 1) reported numerous increased and 


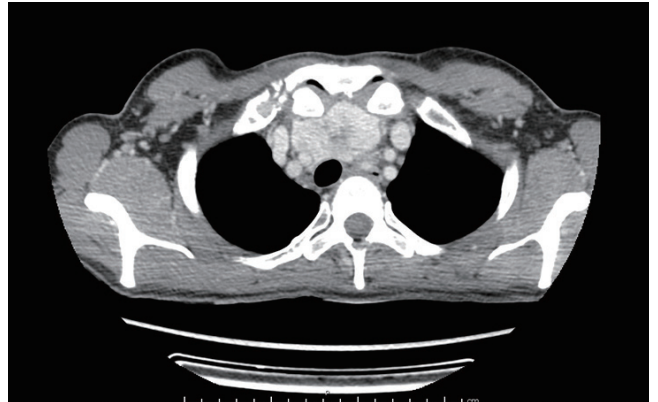

Figure 1 Pre-operative CT-scan of "patient 1". Enlarged lymphadenopathy in the right supraclavicular region and in the superior mediastinum.

vascularized nodulations in the thyroidectomy site, the largest one in correspondence to the surgical clips and on the both sides of trachea; moreover, enlarged lymphadenopathies in the right supraclavicular region and in the superior mediastinum (left pre-vascular region and left paratracheal-paraesophageal sites) were found.

Fine-needle aspiration biopsy (FNA) of right laterocervical lymph nodes revealed cellular elements compatible with thyroid medullary cancer.

A cervicotomy followed by a longitudinal median sternotomy was performed in two steps to perform a radical laterocervical dissection and an extended macroscopic radical mediastinal lymphadenectomy by isolating both the brachiocephalic veins and the epiaortic vessels. Postoperative hospital stay was 7 days after an eventful course. No further therapies were needed after surgery. At the time of the last-follow-up the patient was still alive and without any recurrence's signs.

\section{Patient 2}

A woman, 47-years-old; in 2013 had a laterocervical lymph node biopsy by FNA that revealed a metastasis of neuroendocrine cancer of unknown origin treated with highdose of somatostatin analogue (lanreotide), successfully. In 2019 a thyroid check-up with ultrasound control showed intraparenchymal nodules and cervical lymphadenopathies; a second FNA revealed a thyroid medullary carcinoma. A chest CT-scan showed retrosternal large lymphadenopathy compressing left brachiocephalic vein and the cartilaginous wall of the cervical trachea together with an increased and dishomogeneous thyroid gland.

A total thyroidectomy en bloc with an extended cervical and mediastinal lymph nodes dissection by cervicotomy and then median sternotomy were performed. Lymph nodes were surrounding the epiaortic vessels for a length of $5 \mathrm{~cm}$ from the aortic arch, infiltrating the mammarian vessels and the sternal periosteum and compressing the left brachiocephalic vein (Figure 2). Histopathological examination revealed a thyroid medullary cancer with perithyroid tissues infiltration and multiple lymph nodes metastases [pT2(m)N1M1].

Post-operative hospital stay was complicated by a moderate mediastinal bleeding that required red blood cells transfusion and by a transient dysphonia that was fully recovered in one week.

\section{Patient 3}

A 75-year-old woman was admitted to our department for a cervical-mediastinal extended lesion associated with mediastinal syndrome, progressive face and neck edema and severe dysphagia.

CT-scan showed infiltration of brachiocephalic vein's junction and superior vena cava with endoluminal neoplastic thrombosis by right paratracheal lymphadenopathies, associated to an enlarged and dishomogeneous thyroid (Figure 3).

An endobronchial ultrasound-guided transbronchial needle aspiration (EBUS-TBNA) revealed papillary thyroid carcinoma metastases in the superior and inferior paratracheal lymph nodes. After a multidisciplinary discussion with thoracic, endocrine, cardiac and vascular surgeons, the patient underwent combined surgery.

An enlarged cervicotomy was performed by endocrine surgeon to remove macroscopically all the thyroid gland with the laterocervical lymph nodes, bilaterally. The second step was managed through a median sternotomy. The surgical equipe was consisting of a cardiac, a thoracic and a vascular surgeons who provided an extended dissection of all the lymphadenopathies from the vessels infiltrated or compressed, a left brachiocephalic vein resection and reconstruction with vascular graft, an endoluminal thrombus of the superior vena cava removal by assessing the ECC and opening the right atrium (Figure 4). Because an uncontrollable diffuse minimal blood leaking a mediastinal gauze packing was required, afterward sternotomy was finally closed on the post-operative day 2 , in absence of bleeding. After surgery, the patient was admitted to Intensive Care Unit (ICU) for intensive monitoring. During the hospital stay, the patient developed pleural effusion and bilateral pneumonia that required a tracheotomy after 

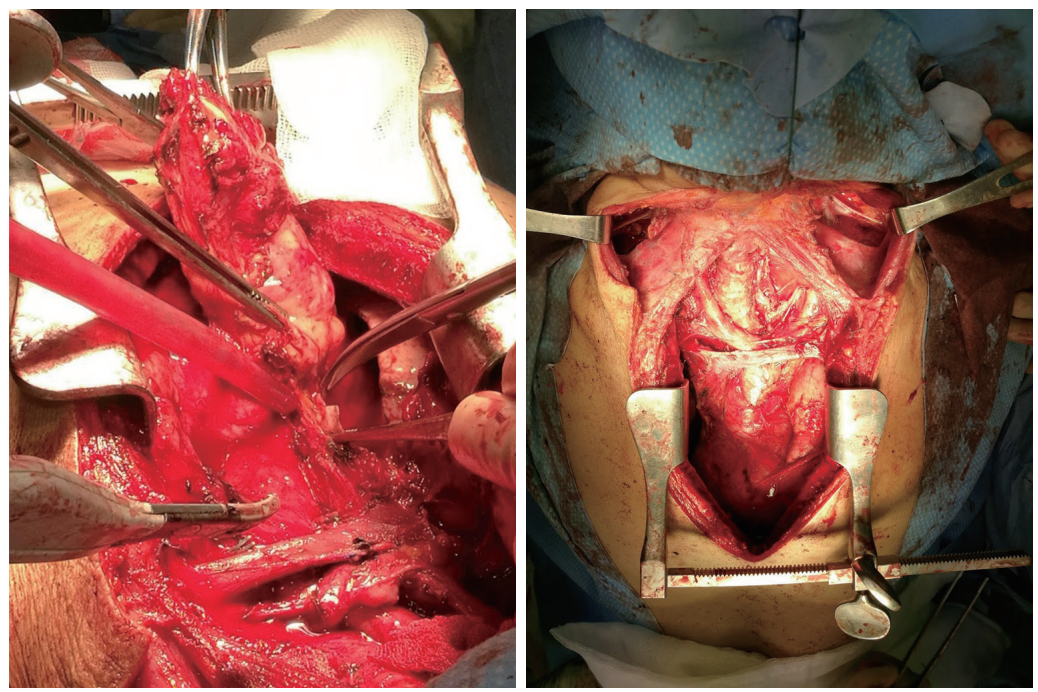

Figure 2 Intra-operative images of "patient 2". Total thyroidectomy en bloc with an extended cervical and mediastinal lymph nodes dissection.

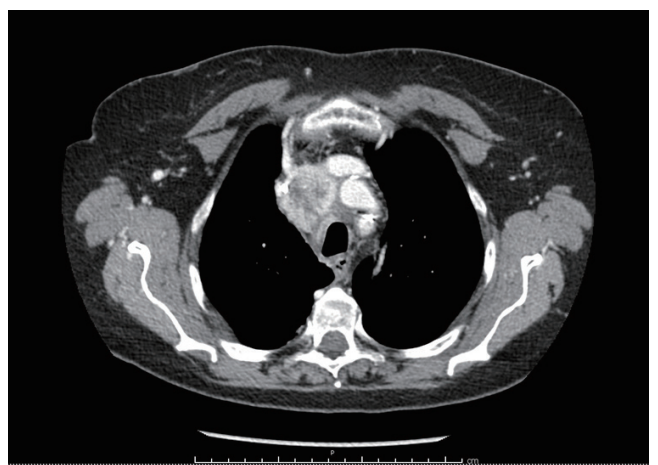

Figure 3 Pre-operative CT-scan of "patient 3". Infiltration of brachiocephalic vein's junction and superior vena cava with endoluminal neoplastic thrombosis by right paratracheal lymphadenopathies.

8 days to guarantee better respiratory gas exchanges and prolonged rehabilitation lasting 100 days.

\section{Patient 4}

A 68-year-old-man underwent FNA of a thyroid nodule in the right lobe and of one inferior right cervical lymph node that revealed a solid undifferentiated thyroid carcinoma.

Total body CT-scan showed the presence of neoplastic thrombosis of the right internal jugular vein, the vena cava until the right atrium (Figure 5) and right thyroid lobe neoplastic mass dislocating and compressing the cervical trachea (Figure 6). A multidisciplinary setting consisting in an endocrine, a thoracic, a cardiac and a vascular surgeon decided for a combined surgery. A radical thyroidectomy by shaving the tracheal wall together with an extended cervical lymphadenectomy en bloc with external right jugular vein and superior vena cava, combined with cavo-atrial thromboarterectomy and vascular reconstruction with cadaveric and polytetrafluoroethylene (PTFE) vascular graft was performed through cervicotomy and sternotomy by using the ECC.

After surgery patient was admitted in Intensive Care Unit, and then was moved to a rehabilitation structure. After two months, for a sternal dehiscence, he was readmitted to our department to a surgical revision.

\section{Discussion}

The mediastinum is a complex structure of the thorax that contains a wide variety of vital organs. An extended surgery in such a narrow space is often burdened by severe complications and require a high level of expertise in managing them (11). In this series no intraoperative or perioperative mortality occurred. Two patients were extubated at the end of the surgery. One patient required a tracheotomy on post-operative day $8^{\text {th }}$ to ensure better respiratory exchanges while one patient was extubated after 2 days for intensive monitoring in ICU.

Two patients $(50 \%)$ had a sternal dehiscence that 


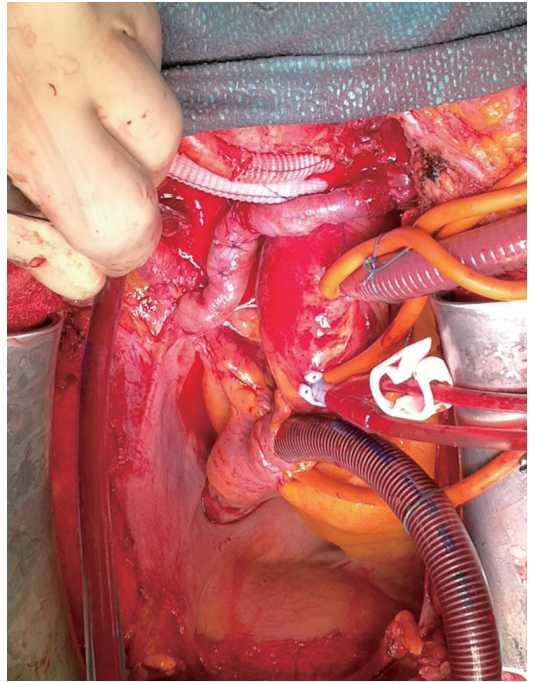

Figure 4 Left brachiocephalic vein reconstructed with cadaveric vascular homograft and endoluminal thrombus of the superior vena cava removal with ECC support.

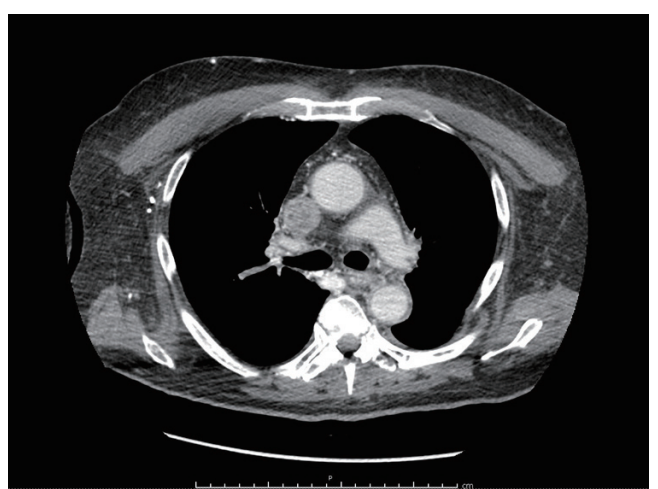

Figure 5 Pre-operative CT-scan of "patient 4". Neoplastic thrombosis of the right internal jugular vein, the cava vena until the right atrium.

required a second surgery and a prolonged ( $>7$ days) postoperative hospital stay, nevertheless none of them developed symptoms like dyspnoea due to trachea-bronchial injury, dysphagia and cough in the post-operative course while one patient presented a dysphonia that was fully recovered in one week. These results are in line with those of other study on this matter $(12,13)$.

In all cases we obtained a macroscopic complete resection (R0) confirmed by the histopathological examination and, up to date, no patient developed a recurrence.

Large mediastinal masses, especially those of neoplastic

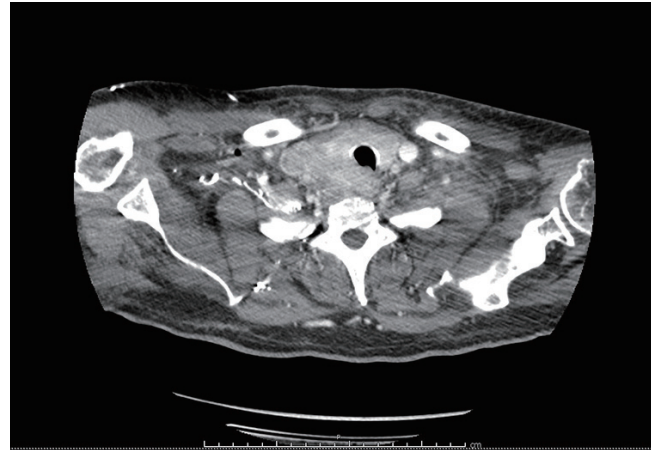

Figure 6 Right thyroid lobe neoplastic mass dislocating and compressing the cervical trachea.

nature, are frequently associated to an impaired anatomy of the surrounding structures and to the abnormal neovascularization. Several authors reported a less invasive approach like a partial upper sternotomy or infra-sternal approach $(11,14)$, however in case of vascular involvement a wider surgical field should be reasonable in order to minimize the bleeding due to vascular damage. In the literature, sternotomy as surgical approach is reported in less than $5 \%$ for overall thyroidectomies performed $(13,15)$. However, most authors support this approach in case of mediastinal node progression or when a complex dissection on the vital structures is required (16).

The role of surgery in the treatment of advanced cases of thyroid carcinoma is a topic of increasing interest thanks to the improvement of the reconstructive surgery technique and accessibility of a wide variety of prosthesis that allow a greater demolitive possibilities, even total pharynx-larynxoesophagectomy or resection of the major mediastinum vessels with a subsequent and effective reconstruction (14-16). Unfortunately, due to rarity of this kind of disease, few literatures are available on this matter, nowadays.

In this series, two patients required vascular reconstruction by graft for metastatic thrombosis. In these situations, was emblematic the essential role of a multicentric team with the help of vascular and cardiac surgeons. No complication related to the vascular graft, like dislocation. No acute bleeding complications occurred.

No complication related to ECC were found in patients who required it (nervous system complications, such as hemorrhagia, ischemia, or multi-organ failure, in particular renal failure).

In according to literature, we divided surgical cervicotomy 
time by sternotomy time for better infection control (in particular to reduce risk of mediastinitis).

Patients with sternal dehiscence and prolonged intubation needed post-operative specific antibiotic drugs but no patient presented post-operative mediastinitis.

\section{Conclusions}

Surgery is more effective than systemic therapy in the treatment of thyroid cancer recurrences, especially for medullary thyroid cancer in which radioiodine therapy (I-131) is ineffective and should always be evaluated in case of vascular infiltration or symptomatic patients.

Radical dissection and a thorough reconstruction allow a long-lasting remission with good living conditions to patients unresponsive to other therapies.

Local control of the disease is the most important oncologic target of extended surgery, together with the symptomatic benefit. Regional eradication or debulking of the tumour mass, resulting in macroscopically radical surgery or in minimal residual disease, allows other therapeutic options such as with metabolic radiation, especially for distant localizations, and conventional radiation for regional oncologic sterilization.

The neck and the mediastinum are complex structures with a wide variety of vital organs. A thyroid cancer that involves both compartments requires a combined approach by involving a multidisciplinary surgical team.

In conclusion this case-series reports the effectiveness of a multidisciplinary surgery in controlling symptoms and achieve a radical resection and a good post-operative quality of life.

\section{Acknowledgments}

Funding: None.

\section{Footnote}

Provenance and Peer Review: This article was commissioned by the Guest Editors (Francesco Zaraca, Reinhold Perkmann, Luca Bertolaccini and Roberto Crisci) for the Focused Issue "Thoracic Surgery Without Borders" published in Current Challenges in Thoracic Surgery. The article was sent for external peer review organized by the Guest Editors and the editorial office.

Conflicts of Interest: All authors have completed the ICMJE uniform disclosure form (available at http://dx.doi. org/10.21037/ccts.2019.11.09). The Focused Issue "Thoracic Surgery Without Borders" was commissioned by the editorial office without any funding or sponsorship. The authors have no other conflicts of interest to declare.

Ethical Statement: The authors are accountable for all aspects of the work in ensuring that questions related to the accuracy or integrity of any part of the work are appropriately investigated and resolved. Written informed consent was obtained from the patient for publication of this manuscript and any accompanying images.

Open Access Statement: This is an Open Access article distributed in accordance with the Creative Commons Attribution-NonCommercial-NoDerivs 4.0 International License (CC BY-NC-ND 4.0), which permits the noncommercial replication and distribution of the article with the strict proviso that no changes or edits are made and the original work is properly cited (including links to both the formal publication through the relevant DOI and the license). See: https://creativecommons.org/licenses/by-nc-nd/4.0/.

\section{References}

1. Burke JP, Hay ID, Dignan F, et al. Long-term trends in thyroid carcinoma: a population-based study in Olmsted County, Minnesota, 1935-1999. Mayo Clin Proc 2005;80:753-8.

2. Mitchell I, Livingston EH, Chang AY, et al. Trends in thyroid cancer demographics and surgical therapy in the United States. Surgery 2007;142:823-8; discussion 828.e1.

3. Porterfield JR, Cassivi SD, Wigle DA, et al. Thoracic metastasectomy for thyroid malignancies. Eur J Cardiothorac Surg 2009;36:155-8.

4. Pak H, Gourgiotis L, Chang WI, et al. Role of metastasectomy in the management of thyroid carcinoma: the NIH experience. J Surg Oncol 2003;82:10-8.

5. Lin JD, Chao TC, Chou SC, et al. Papillary thyroid carcinomas with lung metastases. Thyroid 2004;14:1091-6.

6. McCORT JJ. Intrathoracic goiter; its incidence, symptomatology, and roentgen diagnosis. Radiology 1949;53:227-37.

7. Protopapas AD, Nicholson AG, Vini L, et al. Thoracic metastasectomy in thyroid malignancies. Ann Thorac Surg 2001;72:1906-8.

8. Sarrazin R, Brichon PY, Chaffanjon P. [Mediastinal 
metastasis of differentiated thyroid cancers. Treatment by total mediastinal curettage in 9 cases]. Ann Endocrinol (Paris) 1997;58:242-7.

9. Niederle B, Roka R, Schemper M, et al. Surgical treatment of distant metastases in differentiated thyroid cancer: indication and results. Surgery 1986;100:1088-97.

10. Liu D, Labow DM, Dang N, et al. Pulmonary metastasectomy for head and neck cancers. Ann Surg Oncol 1999;6:572-8.

11. Bacha EA, Chapelier AR, Macchiarini P, et al. Surgery for invasive primary mediastinal tumors. Ann Thorac Surg 1998;66:234-9.

12. Blondeau P. [Substernal goiter: diagnostic and therapeutic problems (apropos of a personal series of 585

doi: $10.21037 /$ ccts.2019.11.09

Cite this article as: Marrama E, Aprile V, Nesti A, Bacchin D, Materazzi G, Lucchi M. Mediastinal lymph node metastases in thyroid cancer: surgery without limits. Curr Chall Thorac Surg 2019;1:26. interventions)]. Bull Acad Natl Med 1994;178:1257-64; discussion 1264-6.

13. Nistor C, Ciuche A, Mota C, et al. Cervico-mediastinal thyroid masses - our experience. Chirurgia (Bucur) 2014;109:34-43.

14. Kido T, Hazama K, Inoue Y, et al. Resection of anterior mediastinal masses through an infrasternal approach. Ann Thorac Surg 1999;67:263-5 .

15. Ahmed ME, Ahmed EO, Mahadi SI. Retrosternal goiter: the need for median sternotomy. World J Surg 2006;30:1945-8; discussion 1949.

16. Russo F, Veneziani A, Rossi P, et al. [The surgical treatment of a differentiated thyroid carcinoma infiltrating the large mediastinal veins]. G Chir 1993;14:31-6. 